\title{
REPRODUÇÃO E ONTOLOGIA EM LUKÁCS
}

Sergio Lessa ${ }^{1}$

- RESUMO: Este artigo tem por objetivo expor os nódulos ontológicos essenciais da categoria social da reprodução, como delineados na obra póstuma de Georg Lukács, Para uma ontolologia do ser social.

- PALAVRAS-CHAVE: Ontologia; repıuuução social; trabalho; Lukács.

....uma tentativa de reconduzir efetivamente o pensamento ao ser, no mundo de hoje, pode ter lugar apenas com o desenvolvimento da ontologia do marxismo. (Lukács, 1979b, p. 33)

No momento em que á maior parte dos pensadores descarta a ontologia como ultrapassada metafísica, em que a quase unanimidade dos especialistas eleva a epistemologia e o positivismo a "doutrinas quase oficiais", Lukács ocupa os últimos anos de sua vida escrevendo Para uma ontologia do ser social (1976-1981). Quais as razões que levaram Lukács, em um período em que a ontologia passa a ser tão desconsiderada, a pesquisar a reprodução social enquanto categoria ontológica?

Como usualmente ocorre com as questões fundamentais, as respostas não são simples. Em se tratando de Lukács, aumenta ainda mais a complexidade da resposta. O pensamento lukácsiano é de tal modo articulado com sua época, que uma resposta minimamente satisfatória envolveria toda uma malha de referências e conexões cujas raízes se situam, com maiores ou menores mediações, nos principais problemas, dilemas e questionamentos postos pela evolução da humanidade neste século. Contudo, de forma sintética e preliminar, talvez seja possível ir ao centro da questão afirmando que, para Lukács, a angulação ontológica se impôs como a única capaz de resgatar o radical caráter histórico e humano do ser social, de modo a, no limite e no essencial, reafirmar a asserção marxiana segundo a qual a história é resultado

1. Professor do Departamento de Filosofia da Universidade Federal de Alagoas - Maceió/Doutorando no Departamento de Ciências Sociais da Universidade Estadual de Campinas. 
exclusivo da ação dos homens e que, por isso, está ao alcance da humanidade tomar a história em suas mãos. As ressonâncias éticas aqui evidentes não são casuais; de fato, Lukács concebe a sua Ontologia como preparatória a uma Ética que, todavia, não viveu o suficiente para escrever.

Este esboço de resposta já nos indica duas das categorias básicas da ontologia lukácsiana do ser social. Em primeiro lugar, enquanto categoria central do mundo dos homens. ${ }^{2}$ Depois, o caráter radicalmente humano desta historicidade: a trajetória global do gênero humano, sua história, é o resultado concreto da reprodução social, uma síntese peculiar que converte em totalidade e em individualidades as incontáveis e distintas ações dos indivíduos singulares (Lukács, 1976-1981, v. II, p. 253-CLVI). ${ }^{3}$

Para Lukács, portanto, não há nada semelhante a uma "natureza" humana dada a-historicamente, de uma vez para sempre, nos moldes de Rousseau ou do senso comum da cotidianidade contemporânea (Lukács, 1979, p. 14; 1976-81, v. II, p. 269-74/CLXV-CLXXII). O homem não é necessariamente bom o u mau, sua história não está traçada a priori por uma força ou tendência pertencente a uma sua essência mais profunda, a qual apenas de modo superficial e transitório seria tocada pela história. Muito pelo contrário. Ao longo de toda sua Ontologia, cada parágrafo é a reafirmação da radical historicidade e sociabilidade do ser humano.

No interior deste balizamento básico, o pensador húngaro, a fim de sustentar seus postulados fundamentais (a historicidade e a sociabilidade do mundo dos homens), conferiu um tratamento peculiar ao tradicional problema ontológico da continuidade. ${ }^{4}$

A categoria da continuidade foi tradicionalmente abordada à luz da dualidade essência-fenômeno. Os traços de continuidade seriam aqueles dados pela essência e corresponderiam ao verdadeiro, duradouro. Por sua vez, os traços de mudança e movimento seriam aqueles oriundos da esfera fenomênica, necessariamente transitória, efêmera. Essência e fenômeno, portanto, distinguir-se-iam como diferentes níveis do ser, e esta diferenciação seria dada por uma maior ou menor "realidade", por uma menor ou maior participação no ser. Essência e fenômeno, continuidade e historicidade, ser e devir, deste modo, são contrapostos enquanto mais ou menos reais, mais ou menos "essenciais" ou "aparentes".

Lukács rompe com esta tradição. Postula a substancialidade enquanto categoria histórica. Em poucas palavras, persegue os nódulos centrais de uma continuidade cujo modo de ser seja histórico, associando intimamente historicidade e continuidade

2. Com isto não queremos sugerir que a historicidade seja uma categoria apenas social. A historicidade, para Lukács, é uma categoria do ser em geral, sem que isso venha a significar uma abstrata homogeneização dos traços distintos que a historicidade assume na natureza e no ser social. Cf., por exemplo, Lukács, 1976-1981, v. II, tomo 1, p. 167.

3. O número romano, nas citações, corresponde à página da tradução para o português do capítulo "La Riproduzione" de Per una ontologia del'essere sociale, anexa a minha dissertação de Mestrado Sociabilidade e individuação - a categoria da reprodução na ontologia de G. Lukács, defendida na UFMG, Belo Horizonte, em 1990.

4. A problemática envolvendo a categoria da continuidade pode ser posta, sinteticamente, nestes termos: até que ponto - e de que maneira - um ente em transformação ainda é o ente original, até que ponto - e como - um ser que se transforma continua a ser o mesmo? 
- e o faz tomando por objeto primeiro o ser social. Ancorado em Marx, concebe uma substancialidade cuja continuidade não se contrapõe ao devir, cuja permanência enquanto ser se constitui em permanente evolução do processo de sua auto-explicitação; cuja essência, em suma, se consubstancia no próprio devir do qual é a essência (1979b, p. 78).

Argumenta Lukács que a continuidade social se distingue da continuidade apenas natural pelo fato de ser o mundo dos homens uma totalidade sintética de atos teleologicamente postos. Por isso, o ser social tem, na consciência, o orgão e o médium da sua continuidade. Em outras palavras, a continuidade social se constitui num processo de acumulação - que, por sua essência, só pode se desdobrar pela mediação de um órgão como a consciência - no qual as experiências passadas não são apenas acumuladas, mas também confrontadas com as exigências e desafios colocados pelo passado e pelo presente, pelas novas demandas e tarefas que a vida, sem cessar, coloca aos homens. Por isso, a continuidade social exibe potencialidades de desenvolvimento absolutamente inéditas em comparação com a natureza. Acima de tudo a continuidade social pode se elevar a um ser-para-si impossível à continuidade natural: o ser humano é o único que pode se reconhecer na sua própria história, o único que tem a possibilidade de modificá-la conscientemente (1976-1981, v. II, p. 181-7/LIX-LXI). Portanto, na ontologia lukácsiana, essência e fenômeno, devir e continuidade, substancialidade e historicidade não mais se distinguem por uma maior ou menor "realidade", por uma distinta participação no ser, mas sim por diferentes momentos, igualmente reais, da processualidade ontológica. Não mais seriam termos antitéticos de uma relação que, no limite, terminaria por excluir um dos pólos, mas sim distintas instâncias, igualmente reais, articuladas pela inextinguível contraditoriedade da auto-explicitação do ser.

Fizemos referência, anteriormente, ao fato de que, para o filósofo húngaro, o ser social é o resultado de uma síntese peculiar que converte em totalidade os inúmeros atos dos indivíduos singulares (1979b, p. 95). Afirmamos, agora, que o desenvolvimento do ser social - a história - é necessariamente contraditório. Devemos, pois, antes de nos voltarmos à problemática da reprodução, esclarecer a aparente contradição entre a unidade que o conceito de totalidade sugere, e a nossa afirmação da inextinguível contraditoriedade do desenvolvimento ontológico.

Unidade e contraditoriedade não são categorias excludentes em Lukács.

O desenvolvimento do ser social, o surgimento de formações sociais cada vez mais complexas, resulta no crescimento extensivo e intensivo dos momentos de heterogeneidade, multiplicando a quantidade e alterando a qualidade das contradições. Todavia, não é menos verdadeiro que este crescimento da heterogeneidade interna do ser social é acompanhado da intensificação e do aumento quantitativo dos laços objetivos, concretos, que articulam os destinos de cada indivíduo aos destinos da humanidade, portanto, do desenvolvimento da unitariedade intrínseca ao ser social.

Pensemos, para não nos alongarmos, no mercado. Ele surge em um determinado estágio do desenvolvimento humano e, a partir de então, a cada novo avanço da 
sociabilidade se complexifica, alarga seu horizonte de ação, impulsiona a divisão do trabalho, faz convergir para si uma quantidade cada vez maior de ações humanas, até se converter num mercado mundial que, hoje, penetra em todos os poros das vidas dos indivíduos. O mercado é uma articulação objetiva entre a vida cotidiana de cada indivíduo e a humanidade, uma expressão da crescente unidade real, socialmente construída, do gênero; e, concomitantemente, é uma unidade que só pode ser construída através da divisão do trabalho, do desenvolvimento das classes sociais, da crescente diferenciação das atividades, dos indivíduos etc. Ou seja, uma unidade cuja explicitação requer o desenvolvimento de uma sociabilidade crescentemente heterogênea. O mercado exemplifica, com nitidez, como a crescente complexificação das formações sociais ao longo da história requer a construção de relações sociais objetivas que tendem a elevar a unidade biologicamente dada do gênero a uma unidade qualitativamente nova, socialmente posta.

Em suma, sempre segundo Lukács, a crescente unidade objetiva do mundo dos homens não se contrapõe - antes requer - que essa unidade se dê entre elementos crescentemente heterogêneos e internamente contraditórios. O ser social, dessa forma, se revela como um autêntico complexo de complexos, uma totalidade crescentemente unitária, heterogênea e contraditória. ${ }^{5}$

Portanto, para Lukács, a postulação da radical historicidade e sociabilidade do ser social - no limite, reafirmando a possibilidade de os homens conscientemente fazerem a história - está indissoluvelmente associada à concepção da substância social enquanto portadora de uma continuidade histórica; de um ser cujo processo evolutivo tem por traço ontológico distintivo a incessante construção de novos patamares de sociabilidade. O mundo dos homens se desdobra numa totalidade crescentemente heterogênea e contraditória e, ao mesmo tempo, cada vez mais fortemente unitária. Recusa, assim, o pensador húngaro, toda concepção a respeito do humano que, de uma forma ou de outra, se enraíze em naturezas, essências etc. a-históricas. Do mesmo modo, rechaça o irracionalismo que toma o desenvolvimento objetivo do ser social como fruto absoluto de acaso. Entre natureza a-histórica e casualidade absoluta, não submetida a leis, Lukács propõe seu tertium non datur: o ser humano enquanto substância essencialmente histórica e social.

\section{Trabalho: momento fundante da reprodução social}

Segundo Lukács, após Marx, o trabalho é a categoria fundante do ser social. Isto significa que é pelo trabalho que o ser biológico homem se constrói enquanto ser

5. Não queremos aqui sugerir que a natureza não se constitua, também, em um complexo de complexos, para Lukács. Todavia, não será este o local para tratarmos desta problemática. Cf. Lukács, 1976-1981, v. II, p. 138/IV-V, p. $177 / \mathrm{LLX}$. 
social. O trabalho, nesse sentido, é tomado como a forma mais simples e fundamental de toda atividade humana, nas palavras de Lukács, como "protoforma de toda atividade humana" (1979b, p. 81-2; 1976-1981, v. II, p. 135/I).

Sempre segundo Lukács, a estrutura essencial do trabalho é uma peculiar relação reflexiva entre a teleologia, entre objetivos previamente delineados na consciência e a objetividade da natureza e da sociedade. Em poucas palavras, a práxis social se caracteriza pela transformação da realidade segundo objetivos previamente traçados pela consciência (1976-1981, v. II, p. 264/XLX).

Entre as finalidades teleologicamente postas e as transformações objetivamente realizadas, há uma inextinguível tensão. Em primeiro lugar, porque, por princípio, não é jamais possível um conhecimento absoluto do setor da realidade sobre o qual se age, já que a realidade está em permanente evolução (1976-198l, v. II, p. 190/LXX; 1979b, p. 108). Em segundo, porque o novo objeto, a nova relação social criada pelo trabalho, adquire uma vida própria, independente - em maior ou menor grau - do seu criador. Assim, tanto a contradição que ocorre entre o objetivo almejado e o resultado efetivamente alcançado, como também o efeito de retorno, sobre o ser social, da trajetória concreta do objeto criado, fornece elementos que comporão o próximo processo de ideação e, dessa forma, adentrarão no novo ciclo de prévia ideação/transformação do real. Este é o modo de ser básico da constante evolução da relação reflexiva que se desdobra entre os objetivos previamente idealizados e os resultados alcançados pelo ato do trabalho (1979b, p. 52-3).

Tal dialética teleologia/causalidade remete Lukács a um outro elemento-chave da categoria do trabalho. Nos referimos ao impulso a generalizar seus resultados e seus processos (1976-1981, v. II, p. 231-2/CXX-CXXI). Este processo de generalização se desdobra em dois níveis que, no processo real, são indissociáveis.

O primeiro nível diz respeito ao processo de generalização que envolve o processo de ideação; isto é, concernente à tendência, intrínseca ao trabalho, a generalizar, no nível da subjetividade, os resultados parciais das experiências singulares presentes em cada ato de trabalho enquanto tal. As experiências, certamente singulares e únicas, envolvidas na construção de um machado, por exemplo, são generalizadas e convertidas em um conhecimento genérico que servirá à construção de qualquer outro machado. Com o tempo esta generalização que, na imediaticidade, se realiza na consciência de um único indivíduo, termina por se generalizar em um outro nível: torna-se coletivo, eleva-se a conhecimento pertencente à formação social como um todo. Esta passagem do conhecimento de um caso singular a um conhecimento com validade universal, bem como a passagem de um conhecimento pertencente a um indivíduo a um conhecimento coletivo, sócio-genérico, são passagens espontaneamente impulsionadas pela dinâmica da práxis social.

O segundo nível se refere ao processo pelo qual os resultados do trabalho são generalizados pelo fluxo da práxis social. Aquisições como um machado mais sofisticado, uma construção lingüística mais apropriada às exigências cotidianas, uma técnica mais adequada à caça etc. são generalizadas pela própria práxis social. E, 
apenas após este processo de generalização, adquirem seu real significado social. De modo análogo, o crescimento das capacidades humanas em transformar a natureza se relaciona intimamente à generalização de relações sociais que, com o tempo, abrangem uma quantidade cada vez maior de homens - até atingir a totalidade da humanidade, como ocorre nos dias de hoje - em uma malha social cada vez mais desenvolvida, mais distante do seu primitivo ponto de partida. Este é o fundamento ontológico da gênese e desenvolvimento de relações sociais que crescentemente articulam os indivíduos ao gênero humano, tornando a substancialidade humana cada vez mais sócio-genérica.

Este impulso à generalização, nos níveis acima expostos, é responsável pela elevação do ser humano a patamares superiores, crescentes, de sociabilidade. É este impulso a raiz do desenvolvimento de relações sociais que tornam o ser humano cada vez mais genérico. Em suma, é a essência da reprodução social. Após Marx, Lukács denomina esse processo de afastamento das barreiras naturais, de processo de sociabilização.

Todavia, o processo de reprodução social não se limita ao processo de trabalho enquanto tal. Indiscutivelmente, sem trabalho não se pode sequer imaginar qualquer processo de reprodução social. Mas não é menos verdadeiro que o processo de evolução social dá origem a necessidades e a mediações sociais para atender a estas necessidades que, embora tenham suas gêneses no processo de sociabilização desencadeado pelo trabalho, não se restringem mais ao processo de trabalho em si. Desse modo, com a complexificação das formações sociais, surgem complexos mediadores como o direito, a fala, a filosofia, a arte, a política, etc. que não mais pertencem ao trabalho enquanto tal, embora tenham a sua gênese nas necessidades postas pelo processo de desenvolvimento social desencadeado pelo trabalho.

É por demais sabido que o marxismo vulgar trabalha com extrema infelicidade, para dizer o mínimo, os problemas que daqui emergem. É gritante a sua desconsideração para com os complexos sociais mediadores operantes na reprodução social. Num simplismo que deformou em profundidade o pensamento marxiano, a especificidade dos complexos mediadores foi deformada até restringi-los a meros epifenômenos da reprodução social - enquanto esta, por sua vez, foi limitada a uma reprodução imediatamente material.

Um dos momentos de evidente ruptura de Lukács com o marxismo vulgar foi a consideração particularizadora que dedicou a este complexo de mediações sociais. Entre a categoria do trabalho enquanto tal e a processualidade social global, compondo a malha de mediações reais que articulam trabalho e totalidade social, Lukács assinala a presença de uma categoria peculiar, que não se confunde com o trabalho, ainda que dele se origine, que é a categoria da reprodução social. ${ }^{6}$

6. Argumenta o filósofo húngaro que esta categoria, a da reprodução social, pode ser encontrada já nos textos marxianos, estando, portanto, absolutamente incorporada aos delineamentos ontológicos desenvolvidos por Marx. A veracidade deste fato, todavia, não deve velar uma outra esfera de problemas, à qual, agora, apenas faremos referências: se é correto que podemos encontrar a categoria da reprodução como central já nos escritos marxianos, 
Com isso chegamos ao tema do nosso artigo, o processo da reprodução social na ontologia de Lukács.

\section{A bipolaridade da reprodução social}

Segundo Lukács, a questão chave no estudo da reprodução do mundo dos homens é o desvelamento da síntese peculiar que, a partir dos atos singulares dos indivíduos concretos, funda uma nova substancialidade, cuja essência é o processo de sociabilização (1976-1981, v. II, p. 287-8/CLXXXVII-VIII), Já vimos que o momento fundante desta síntese é o trabalho; que a tendência à generalização, inerente ao trabalho, é a gênese da sociabilidade. Trata-se, portanto, de buscar as articulações ontológicas pelas quais o ato singular se consubstancia no elemento fundante, tanto da individualidade como da totalidade social.

Lukács inicia esta busca assinalando que a dialética teleologia/causalidade, nódulo essencial do trabalho, faz com que a totalidade social apenas possa se explicitar categorialmente, tendo por órgão e médium a consciência. E como a consciência é sempre, na sua imediaticidade, a consciência concreta de um indivíduo concreto, a crescente complexificação das formações sociais requer individualidades cada vez mais ricas e articuladas, capazes de atos cada vez mais socialmente mediados. Por isso, o processo de acumulação que caracteriza a reprodução social necessariamente resulta em modificação e complexificação das individualidades que lhe servem de médium (1976-1981, v. II, p. 226-7/CXV-VII, p. 268-9/CLXV).

Em outras palavras, por ter como órgão e médium de sua continuidade a consciência dos indivíduos concretos, o desenvolvimento do ser social também requer e favorece o desenvolvimento, a complexificação, das individualidades. Estas se distanciam, cada vez mais, de sua origem, em que cada indivíduo muito tenuamente se distinguia, na sua vida cotidiana, tanto dos outros indivíduos, como da totalidade da formação social à qual pertencia. A continuidade dessa linha de desenvolvimento resultou na elevação à consciência, em escala social, do fato de a reprodução social envolver dois momentos distintos, ainda que inseparáveis: a reprodução do indivíduo enquanto individualidade; e a reprodução da formação social na sua totalidade. No dizer de Lukács, resultou na consciência do caráter bipolar da reprodução social.

não menos verdadeiro é o fato de que, em Lukács, esta categoria ganha um peso e uma abrangência na processualidade social que, se não a contradiz, ao menos não é a mesma que encontramos em Marx. Talvez, na sua firme determinação de se contrapor frontalmente ao marxismo vulgar, tenha o filósofo húngaro sublinhado em demasia a especificidade da categoria da reprodução social ante o trabalho enquanto tal. A resolução cabal dessa esfera de problemas envolveria um estudo dos escritos de Marx que tivesse em vista determinar com clareza a categoria da reprodução em suas teorizações e, em seguida, compará-la com a teoria de Lukács - tarefa que, até o momento, não foi ainda realizada. Assim, fica aqui apenas indicada uma esfera de problemas que ainda está à espera de um estudo mais abrangente. 
Vale ressaltar que, sempre segundo Lukács, o caráter bipolar da reprodução social é um traço ontológico específico do mundo dos homens (1976-1981, v. II, p. 182/LV). Tal é, na ontologia lukácsiana, o traço ontológico distintivo entre a reprodução social e a natural. Ao contrário do que encontramos na natureza, no ser social a constante superação do ponto de partida originário, apenas em-si, explicita no plano objetivo, e eleva à consciência em escala social, o caráter bipolar da sua reprodução; isto é, a individuação e a sociabilidade consubstanciam momentos distintos de uma mesma processualidade reprodutiva global. Deste modo, ao longo do processo reprodutivo, as individualidades vão se compondo, ao mesmo tempo, como personalidades crescentemente particulares e crescentemente genéricas.

Isto posto, devemos passar à análise da reprodução da sociedade como um todo e à da individuação.

\section{A individuação}

Para Lukács, se o ser social é a síntese dos atos singulares em tendências, forças genéricas, então a substância concreta que distingue uma individualidade das demais (bem como da totalidade social) é dada pela qualidade, direção etc. da cadeia de decisões alternativas que constitui a sua existência. É a qualidade das relações estabelecidas com o mundo que o cerca que ontologicamente caracteriza a substancialidade de cada indivíduo singular (1976-1981, v. II, p. 261-2/CLVI-VIII, 227/CXVI).

Isto significa que, para o filósofo húngaro, o indivíduo humano se distingue radicalmente do espécime biológico singular. Este possui uma substancialidade dada de uma vez por todas em sua herança genética (1976-1981, v. II, p. 177-8/LIV-V). O indivíduo humano, pelo contrário, constrói sua substancialidade social ao longo de sua vida, escolhendo entre as diferentes alternativas descortinadas pela realidade. A substancialidade do indivíduo humano, portanto, não apenas é radicalmente social, como também histórica: nem mesmo as características herdadas biologicamente pelo indivíduo podem determinar a priori qual será a dinâmica de evolução de sua personalidade.

Isto também significa que a construção da personalidade de cada indivíduo apenas é possível em intensa integração com a formação social a que pertence. A absoluta necessidade desta articulação com a totalidade social para que a individualidade possa se explicitar categorialmente se manifesta e se fundamenta, segundo Lukács, em três momentos-chave: o primeiro momento corresponde ao fato de ser o desenvolvimento objetivo do ser social, como um todo, o processo de afastamento das barreiras naturais que, ao mesmo tempo, possibilita e requer o desenvolvimento de personalidades cada vez mais ricas, mediadas e complexas. Por esta mediação, o impulso à generidade inerente ao próprio trabalho se constitui no fundamento ontológico último do processo de individuação. Em suma, para Lukács, o indivíduo 
humano apenas tem existência real enquanto ente social. Fora da sociedade, não há qualquer individuação possível (1976-1981, v. II, p. 261-2/CLVI-II).

Em segundo lugar, a individuação apenas pode se realizar em sociedade porque o seu elemento fundante, as ações dos indivíduos, apenas existe enquanto síntese de elementos genéricos e particulares. Os elementos genéricos são dados: 1) pela demanda específica, sempre posta pela sociedade, que está na raiz de todo ato; 2) pela ação de retorno do produto criado para o seu criador; 3) e, finalmente, pelos avanços sociogenéricos que são incorporados às consciências individuais pelo fluxo espontâneo da práxis social. Os elementos particulares, por sua vez, se originam: 1) na singularidade de cada situação; 2) na singularidade de cada individualidade; 3) e, por fim, na singularidade da resposta que corresponde à alternativa escolhida (1976-1981, v. II, p. 327 ss).

Salientemos que, em Lukács, todo ato social é uma unidade sintética de elementos genéricos e singulares (1976-1981, v. II, p. 276-7/CLXXIV-VI). Os três momentos anteriormente assinalados, no plano da realidade objetiva, substanciam uma unidade sintética, de tal modo que, apenas teórica e abstratamente podemos separá-los. Na cotidianidade, os elementos genéricos e particulares estão de tal forma articulados, que freqüentemente exigem análises cuidadosas para que se distinga um do outro. Todavia, esta inseparabilidade dos elementos genéricos e particulares não significa que eles tenham desaparecido enquanto tais. Pelo contrário, eles apenas podem contribuir para o processo de particularização que faz cada ato humano diferente de todos os outros, mas sempre partícipes da história, na medida em que desdobram uma tensão entre a generidade e a particularidade, tensão esta que permeia a concretude particular de todo ato.

Assinala Lukács que esta tensão entre os elementos genéricos e os particulares cumpre uma função ontológica específica: é o médium que permite, no nível da práxis cotidiana, a percepção da contraditoriedade gênero humano/individualidade. É esta tensão que, na escolha das inúmeras alternativas ofertadas pelo real, faz com que o indivíduo tenha que escolher entre possibilidades mais ou menos genéricas, ou mais ou menos particulares.

É esta a conexão na qual se articula o terceiro momento da individuação. O desenvolvimento das individualidades apenas é possível na presença de complexas mediações, necessariamente genéricas, que permitam ao indivíduo referir a si próprio as exigências postas pela evolução do gênero humano. É assim que surgem os costumes, o direito, a ética etc., para atender à necessidade, permanente na reprodução social de os indivíduos remeterem a si próprios, como suas, as necessidades postas pelo desenvolvimento humano genérico. Nesta medida, tais mediações desempenham um papel fundamental no desenvolvimento interno, peculiar, a cada individualidade.

Como veremos logo a seguir, neste terceiro momento os valores têm um peso ontológico que não deve ser desprezado, principalmente em se tratando das sociedades mais avançadas. Eles impulsionam as individualidades a posições teleológicas 
mais socialmente mediadas, mais genéricas, valorizando positivamente as reais exigências postas pelo desenvolvimento da humanidade enquanto gênero ou, pelo contrário, estimulando a adoção de alternativas centradas na particularidade da individualidade, que se compreende como mônada. As conseqüências práticas, imediatas, para a individuação são imediatamente visíveis na sociedade contemporânea, pois a opção pelos valores genéricos pode elevar a substancialidade de cada individualidade à generidade - ou, pelo contrário, a opção pelos valores meramente particulares pode rebaixar o conteúdo da sua existência à mesquinhez do universo do bourgeois que se contrapõe/sobrepõe à humanidade.

Portanto, para Lukács, são três os nexos ontológicos fundamentais que possibilitam a síntese dos atos singulares em um processo de individuação: 1) o processo de sociabilização é o seu impulso fundante e o seu momento predominante; 2) a contraditoriedade entre os elementos genérico-universais e os particulares, em todo ato singular, contraditoriedade esta potencializada pela explicitação categorial da bipolaridade característica da reprodução do mundo dos homens, força os indivíduos a tomarem consciência da relação contraditória que permeia a relação indivíduo/sociedade; e, 3) o desenvolvimento de uma malha de relações sociais crescentemente genérica é o fundamento ontológico da necessidade e, ao mesmo tempo, possibilidade, de, no processo de reprodução, atuarem valores e processos valorativos cada vez mais genéricos (Lukács pensa, acima de tudo, na ética). Estes três nexos, segundo Lukács, são o fundamento ontológico último para que a reprodução do indivíduo, ao mesmo tempo em que apenas possa se desdobrar no interior de relações sociais, explicite uma crescente autonomia ante a reprodução social global, na medida em que consubstancia o seu para-si.

\section{A sociabilidade}

Tal como na individuação, a reprodução da totalidade social exibe, segundo Lukács, três momentos fundamentais.

O primeiro momento de síntese da totalidade social se enraiza no nódulo mais essencial do mundo dos homens, o processo de generalização inerente à categoria do trabalho. Esse processo de generalização, ao articular, pelo fluxo da práxis social, cada ato singular com a processualidade social global, constitui o ato singular em elemento primário da totalidade social (1976-1981, v. II, p. 261-CLVI).

O segundo nexo, que opera na síntese da substancialidade social enquanto totalidade, está intrinsecamente relacionado ao anterior: a inextinguível contraditoriedade entre os elementos genéricos e particulares. Já vimos que, no seu nódulo mais essencial, o trabalho produz uma inextinguível tensão entre singularidade e universalidade. Argumentamos, então, como, pelo trabalho, a singularidade da situação concreta se generaliza tanto ao ser confrontada com o passado e o futuro, como 
também ao ser objetivada em um produto (sempre singular) do trabalho. No próprio núcleo mais essencial do trabalho, portanto, as esferas da universalidade e da singularidade estão articuladas em determinações reflexivas.

Essa situação originária, primária, se desdobra, no fluxo da práxis social mais desenvolvida, em um outro nível de contraditoriedade entre os momentos singulares e os universais. A processualidade social global, no seu próprio movimento concreto, cotidiano, coloca o gênero humano diante de alternativas que o forçam a escolher entre as necessidades, interesses e valores humano-genéricos e as necessidades, interesses e valores apenas particulares. Nas sociedades de classe, via de regra essas opções se colocam sob a forma do predomínio do interesse de uma classe sobre os interesses da totalidade social.

Já vimos, ao tratarmos da individuação, o papel central que esta tensão desempenha no processo de elevação da singularidade à individualidade. No nível da reprodução social, esta tensão é a base do fato de todo conflito social, por mais simples, exibir no seu nódulo mais essencial esta contraditoriedade entre o genérico e o particular. Sendo breve, para Lukács, sem esta contraditoriedade não haveria conflitos sociais.

Tal é a base social objetiva, o fundamento ontológico, para que a humanidade, ao longo da história, se eleve a patamares superiores de consciência da contraditoriedade entre os momentos sociogenéricos da reprodução e aqueles apenas particulares; e, conseqüentemente, para que explicite a possibilidade de levar avante sua reprodução de maneira crescentemente consciente. (1976-1981, v. II, p. 327 ss.).

Vimos, até aqui, dois dos nexos operantes na síntese da substancialidade social enquanto totalidade: 1) a generalização inerente à categoria do trabalho que torna social (isto é, socialmente genérico) todo ato singular: e, 2) a inextinguível tensão entre os elementos genéricos e os particulares, que constitui a base para a elevação à consciência, em escala social, do caráter genérico do ser humano. Devemos, agora, prosseguir com a análise do último nexo dessa síntese, o qual nos conduzirá, tal como ocorreu no estudo da individuação, à problemática dos valores e processos valorativos. ${ }^{7}$

Com o desenvolvimento da sociabilidade e a conseqüente intensificação e extensão, tanto objetiva quanto subjetiva, dos conflitos entre os elementos genéricos e os particulares, surge a necessidade de mediações sociais que explicitem, tão nitidamente quanto possível, as exigências genéricas que vão gradativamente se desenvolvendo. ${ }^{8}$ É necessário identificar as necessidades genéricas, plasmá-las em formas sociais que sejam visíveis nas mais diversas situações, para que elas se tornem operantes na cotidianidade. Valores como justiça, igualdade, liberdade etc. surgem a cada período histórico como expressões concretas, historicamente determinadas, das

7. Como se sabe, a ontologia de Lukács foi pensada como introdução a uma obra sua inteiramente dedicada à ética. T'odavia, a morte do filósofo em 1971 interrompeu sua elaboração, apenas permanecenclo algumas anotações que não forarn, até o presente momento, publicaclas

8. As considerações mais signnificativas acerca da ètica são encontraclas em Lukács, 1976-1981, v. II, p. 328-9, trad. S. Lessa, op. cit., p. CCXXXV-VI. CI. th. I. sssa, S., Sociabilidade e individuaçăo, op. cit., p. 127-35. 
necessidades genérico-coletivas postas pelo desenvolvimento da sociabilidade. Certamente, por serem expressões concretas, históricas, das necessidades humanogenéricas, o conteúdo desses valores se altera com o passar do tempo. Tais mudanças introduzem novos problemas nesse complexo, mas não alteram o fato de que tais valores são centrais na elevação à consciência, em escala social, da contradição singular/universal, gênero/indivíduo; e que, por sua vez, a elevação do patamar de consciência da contradição indivíduo/gênero influencie decisivamente na identificação mais precisa das necessidades genéricas historicamente surgidas.

A necessidade social de tais mediações, segundo Lukács, é o fundamento ontológico da gênese e desenvolvimento de complexos como a tradição, a moral, os costumes, o direito e a ética. Cada um deles, apesar das enormes diferenças que apresentam se comparados entre si, tem como função social atuar no espaço aberto pela contraditoriedade entre o genérico e o particular, de modo a tornar reconhecível pelos homens (sempre em escala social) a forma e o conteúdo que, a cada momento, assume essa contraditoriedade. E, assim fazendo, permitem aos homens optarem, de modo cada vez mais consciente, entre valores que expressam as necessidades humano-genéricas e valores que exprimem os interesses apenas particulares de indivíduos ou grupos sociais.

A sociedade burguesa, em particular, ao contrapor indivíduo-mônada/sociedade-composta-pelos-conflitos-entre indivíduos, opõe cotidianamente aos elementos particulares (que freqüentemente assumem a feição de interesses "reais" do indivíduo) os interesses genéricos (que via de regra assumem a aparência de "obstáculos" ao desenvolvimento do indivíduo). E, por esta via, no dia a dia, o indivíduo é forçado, com intensidade inédita diante das formações sociais anteriores, a tomar consciência dessa contraditoriedade e a fazer opções por um ou outro pólo. Sobre essas opções, de maneira cada vez mais predominante, agem os laços genéricos que articulam, de forma cada vez mais intensa, as vidas dos indivíduos ao destino da humanidade. É este o fundamento para que o desenvolvimento de valores cada vez mais genéricos tenha um peso crescente na reprodução da sociedade como um todo.

Nesse processo de elevação da humanidade à generidade, argumenta Lukács, cabe à ética um papel de primeira importância. E aqui, tal como em outros momentos, ao tratar deste complexo social, o filósofo húngaro se limita a apontar sua constituição ontológica fundamental, remetendo à obra que escreveria em seguida, o seu tratamento exaustivo. Sucintamente, para Lukács, o que distingue a ética do costume, do direito etc. é o fato de que, enquanto estes se movem no interior da contradição entre a particularidade da existência individual e a generidade, na ética esta contraditoriedade é superada por uma nova síntese: o ser-para-si do ser social, que agora se realiza tanto no pólo individual quanto no genérico. Neste contexto, a ética seria a expressão e o instrumento da superação do novo patamar da contradição indivíduo/sociedade, possibilitado pela formação social capitalista; seria a mediação social específica que permitiria, à forma burguesa de individualidade burguesa, que se entende meramente particular, superar a si própria, se elevando à generidade, se construindo enquanto 
individualidade conscientemente partícipe de um gênero que se reconhece enquanto tal (1976-1981, v. II, p. 328/CCXXXV).

Frisemos, para evitar qualquer equívoco, que, segundo Lukács, esta nova síntese representada pelo ser-para-si do gênero não significa a eliminação da esfera da particularidade (1976-1981, v. II, p. 328-9/CCXXXVI-VII). A rigor, para o filósofo húngaro, a eliminação da particularidade, da individualidade, é uma impossibilidade ontológica: o ser social é necessariamente composto por indivíduos que se desenvolvem em individualidades, e, por isso, a esfera da particularidade é indestrutível. A superação da particularidade a que nos referimos no parágrafo acima, portanto, deve ser entendida num sentido muito preciso. É a superação da forma estranhada como a particularidade emergiu na consciência dos homens em escala social durante 0 período de ascensão da burguesia ao poder. É a superação da individualidade que se compreende - e, portanto, se comporta - como contraposta e superior ao gênero, que valoriza a sua esfera específica de interesses e vontades como superior às necessidades postas pelo gênero no seu desenvolvimento, da individualidade estreita e mesquinha que caracteriza o bourgeois.

Vale salientar, já que o marxismo freqüentemente é acusado de não ter pensado nem a individualidade, nem as questões relativas à subjetividade, que a superação da particularidade pensada por Lukács não se assemelha em nada ao padrão ético que tão miseravelmente tem marcado a vida nas sociedades pós-revolucionárias ou nos partidos ditos comunistas, se tomados na sua globalidade mais ampla. Não se trata de menosprezar as exigências reais e concretas postas pelo desenvolvimento de cada individualidade em si mesma, mas sim de liberar as individualidades e seus processos evolutivos, sempre peculiares, das travas impostas pelos estranhamentos que brotam da vida sob o capital.

A ontologia lukácsiana, longe de desprezar a esfera da individualidade, a considera fundamental para o desenvolvimento do gênero ao seu ser-para-si (19761981, v. II, p. 256/CL); e, por isso, aponta a necessidade de liberar seu desenvolvimento dos obstáculos colocados por um mundo estranhado que toma o capital, e não o gênero humano, como eixo aglutinador do ser e das atividades humanas. Nesse contexto, a esfera da subjetividade tem um peso essencial. As generalizações, subjetivamente realizadas e mantidas, que brotam do fluxo da práxis social, não apenas fundam 0 mundo dos homens, mas o conduzem, por relações e processos valorativos cada vez mais sociais, mais elevados, a uma elevação do nível da generidade da reprodução social. São determinantes, acima de tudo, no desdobramento concreto da evolução do gênero em direção ao seu ser-para-si. Portanto, para Lukács, tanto a esfera da individualidade como da subjetividade são centrais - ao lado da reprodução da totalidade social e dos produtos objetivos genéricos que dela emergem - na história dos homens.

Que, para Lukács, o fundamento último da processualidade de construção do ser-para-si do gênero humano seja o desenvolvimento objetivo dos laços que crescentemente articulam indivíduo/humanidade, é algo que não necessitamos repetir. $O$ 
que nos interessa realçar agora, com vigor, é o fato de, segundo Lukács, nesta construção do ser-para-si do gênero, os valores jogarem um peso ontológico notável. A decisão específica, novamente em escala social, de se construir na práxis cotidiana a superação da dicotomia particularidade/sociabilidade desenvolvida sob o capital, requer decisões alternativas que só podem vir-a-ser se impulsionadas por valores e processos valorativos que encarnem e expressem adequadamente as necessidades reais postas pelo desenvolvimento do gênero. Daí a importância de uma ética para a constituição de um gênero efetivamente genérico, do ser-para-si do mundo dos homens (1976-1981, v. II, p. 328-9/CCXXXVI).

Em suma, os nexos-chave do processo de síntese que constitui a reprodução social têm sua gênese ontológica no trabalho, no processo de sociabilização que ele desencadeia. A essência desse processo, como vimos, é a elevação do gênero à generidade, ao seu ser-para-si, que funda a polaridade reprodução do indivíduo/reprodução da formação social global.

O processo de individuação tem seu fundamento último no desenvolvimento de formações sociais cada vez mais complexas que, ao mesmo tempo que possibilita, requer imperativamente o desenvolvimento de individualidades dotadas de personalidades cada vez mais complexas, mais ricamente mediadas do ponto de vista social. O médium social objetivo que, a partir de um dado momento histórico, na práxis cotidiana, permite a elevação dos indivíduos à consciência do caráter bipolar da reprodução social, tem suas raízes no caráter complexo de todo ato humano. Cada ato é uma síntese de elementos genéricos e particulares, síntese esta que, longe de eliminar as esferas da generidade e da particularidade, as articula objetivamente em uma totalidade concreta através da qual a tensão entre generidade e particularidade se explicita objetivamente. Tal contraditoriedade generidade/particularidade, repetimos, é o médium objetivo que permite que os indivíduos tomem consciência não apenas do caráter bipolar da reprodução social, mas também da inseparabilidade ontológica indivíduo/ser social. Nesse contexto, se desenvolvem valores e processos valorativos para darem conta das necessidades que brotam da explicitação desta contraditoriedade. A tradição, o direito, os costumes e a ética são algumas das mediações sociais que surgem para atender aos graves problemas e às igualmente generosas possibilidades que daí emergem para a história humana.

O processo de reprodução do complexo social, por sua vez, tem o mesmo fundamento que a individuação, isto é, o processo de socialização desencadeado pelo trabalho. Tal como na reprodução dos indivíduos, a gênese do capitalismo enquanto primeira formação socialmente pura é um momento fundamental: ele permite a explicitação da polaridade indivíduo/sociedade em um novo patamar, que Lukács denomina dualidade generidade/particularidade. Nesta nova dualidade, a essência é a dicotomia citoyen/bourgeois estabelecida pela consciência do homem comum submetido à cotidianidade do capital. A superação dessa dualidade estranhada, por sua vez, é possível, em primeiro lugar, porque os conflitos sociais forçam cotidianamente a escolha entre a esfera da particularidade e a da generidade, obrigando os 
homens a tomarem consciência dessa contraditoriedade; em segundo lugar, porque o desenvolvimento objetivo das forças produtivas origina laços sociais genéricos cada vez mais intensos entre os indivíduos; e, por fim, porque o avanço da sociabilização dá origem a valores e complexos valorativos que impulsionam no sentido genérico.

\section{Conclusão}

Com isso estão delineados, de forma introdutória, os nódulos centrais operantes na reprodução social, segundo Lukács. É necessário, apenas, salientar o óbvio: a reprodução do indivíduo e a reprodução da sociedade como um todo são, para Lukács, pólos de um mesmo processo reprodutivo global, pólos estes que desenvolvem entre si uma relação de determinação reflexiva. Nesse sentido, Lukács rejeita como falsas tanto as teorias que tomam o indivíduo como um ente ontologicamente dissociado do complexo social, como também as teorias que compreendem o complexo social total como o único momento de determinação do seu processo reprodutivo.

Em sua máxima generalidade, esta situação corresponde, no plano da reprodução social, àquilo que Hegel denominou identidade da identidade e da não-identidade. Temos aqui uma necessidade originalmente unitária, a reprodução social que, no seu desenvolvimento, ao mesmo tempo em que origina complexos e mediações sociais cada vez mais desenvolvidas e heterogêneas entre si, também desenvolve nexos e conexões entre eles que unificam as suas processualidades, sempre específicas, em totalidade cada vez mais unívoca. A crescente heterogeneidade entre as individualidades (tanto internamente como entre elas) e a totalidade social, o fato de cada uma delas desenvolver uma legalidade específica cada vez mais atuante na sua própria evolução, nada mais é senão a forma superior de manifestação da necessidade originária de reprodução do mundo dos homens. Em poucas palavras, a forma especificamente social de consubstanciação da unitariedade ontológica do mundo dos homens se desdobra historicamente no desenvolvimento dos elementos de heterogeneidade que compõem a totalidade social. Ou, dito de outro modo, a intensificação da presença dos laços genéricos na reprodução social requer o desenvolvimento de individualidades cada vez mais heterogêneas e específicas: justamente a identidade da identidade e da não-identidade a que nos referimos anteriormente.

Este rápido delineamento dos nódulos centrais da reprodução social, segundo Lukács, evidencia aquele conjunto de balizamentos ontológicos com o qual iniciamos este artigo. Nos referimos à postulação, central na ontologia lukácsiana, da radical historicidade e sociabilidade do mundo dos homens. Vimos como a partir da práxis social o indivíduo, ao agir, ao responder às necessidades postas ao seu desenvolvimento pela realidade que o cerca, concomitantemente contribui à construção do ser social enquanto gênero e à construção da sua individualidade específica. As contradições entre generidade e particularidade, constituintes essenciais tanto do ato em sua singularidade como da processualidade social global, compõem as mediações 
sociais reais da elevação à consciência, em escala social, da bipolaridade indivíduo/sociedade. Vimos como a partir de um determinado estágio do desenvolvimento social, dado pelo capitalismo, esta situação ontológica ganha uma nova qualidade, permitindo, na práxis cotidiana e de forma bastante concreta, a escolha, pelas individualidades e pelo gênero no seu todo, de um novo patamar de existência - isto é, de uma existência social que tome como centrais as reais exigências postas pelo desenvolvimento do gênero humano, superando a centralidade do capital.

O que desejamos salientar nestes parágrafos conclusivos é a oposição frontal da ontologia lukácsiana a toda interpretação do mundo dos homens que tenha como suporte a concepção de uma natureza humana que não seja construto histórico-social. Em suma, para Lukács, os homens se constroem homens, a humanidade se constrói enquanto ser social e, por isso, está aberta a possibilidade de, a partir de um dado patamar de desenvolvimento, a humanidade objetivar esta construção de modo consciente, teleologicamente posto. Em suma, está aberta a possibilidade - no plano ontológico-histórico mais geral, que certamente não significa hoje ou amanhã - de um "assalto aos céus".

Este é, a nosso ver, o cerne do caráter revolucionário da ontologia lukácsiana. Ainda que problemas possam ser localizados aqui e ali, e mesmo por ser uma obra póstuma o que contribui em muito para a presença de lacunas e passagens obscuras, o último esforço sistemático do filósofo húngaro resultou em uma importante reflexão que se contrapõe à maré montante do pensamento conservador; fundamentalmente, ao buscar articular ontologicamente, com base na radical historicidade e sociabilidade do mundo dos homens, como postuladas por Marx, a possibilidade - que não implica cega necessidade - de ruptura com os estranhamentos emanados do capital.

Isto posto, a resposta à pergunta do início deste ensaio, sobre a razão de Lukács ter se voltado à ontologia, pode ser melhor compreendida: explicitar o caráter ontológico da obra marxiana, no que ela se contrapõe à ontologia tradicional (incluindo neste termo abrangente a lógica-ontológica de Hegel) e no que ela é devedora desta mesma ontologia, constitui, para o filósofo húngaro, o terreno mais adequado para uma confrontação cabal com todas as correntes de pensamento que, no essencial, negam a possibilidade de os homens virem a construir a sua própria história de modo consciente, se libertando dos estranhamentos responsáveis pela gênese e desenvolvimento de uma formação social cuja essência é a negação do humano. Tal é, acreditamos nós, o significado mais profundo da ontologia de Georg Lukács.

LESSA, S. Reproduction and ontology in Lukács. Trans/Form/Ação, São Paulo, v. 17, p. 63-79, 1994.

- ABSTRACT: This article aims to discuss the most fundamental nexus of the social category of reproduction, as outlined in Lukács posthumous work Per una ontologia dell'essere sociale.

- KEYWORDS: Ontology; social reproduction; labour; Lukács. 


\section{Referências bibliográficas}

1 LESSA, S. Sociabilidade e individuação - a categonia da reprodução na ontologia de G. Lukács. Belo Horizonte; 1990. Dissertação (Mestrado) - Universidade Federal de Minas Gerais.

2 LUKÁCS, G. Per una ontologia dell'essere sociale. Roma: Riuniti, 1976-1981.

3 A falsa e a verdadeira ontologia de Hegel. São Paulo: Ed. Ciências Humanas, 1979a.

4

Os princípios ontológicos fundamentais de Marx. São Paulo: Ed. Ciências Humanas, 1979b. 